\title{
LIXO DOMICILIAR BRASILEIRO: MODELOS DE GESTÃO E IMPACTOS AMBIENTAIS ${ }^{1}$
}

\author{
BRAZILIAN HOUSEHOLD GARBAGE: MODELS OF MANAGEMENT \\ AND ENVIRONMENTAL IMPACTS
}

\author{
ORDURES MÉNAGÈRES BRESILIEN: MODÈLES DE GESTION \\ ET IMPACTS ENVIRONNEMENTAUX
}

\author{
Maurício Waldman - Universidade de São Paulo - São Paulo - São Paulo - Brasil \\ mw@mw.pro.br
}

Resumo

A questão de uma gestão de excelência para a disposição final dos resíduos sólidos brasileiros tem se tornado um tema recorrente em vários segmentos sociais e de especialistas. Para além de problema sanitário, o gerenciamento do lixo tem interfaces nítidas com a questão ambiental e destaca-se como procedimento fundamental para as administrações municipais. No geral, o monitoramento dos resíduos ainda apela para equipamentos carentes de conteúdo técnico (lixões) ou, então, para aterros sanitários cuja gestão também é objeto de objeções técnicas. A escalada na geração de resíduos urbanos tem provocado escassez crescente de áreas para disposição final, sugerindo, pois, a incineração como solução para a destinação dos rejeitos. Contudo, o processo térmico insere elementos ambientalmente complicadores, implica capacitação técnica e um serviço público eficiente, premissas que interferem decisivamente na implantação dos incineradores. 0 lixo domiciliar brasileiro, um dos grandes montantes na escala mundial, solicita um modelo de gestão que priorize a revisão dos processos geradores de resíduos, a começar pelos hábitos de consumo, e que, igualmente, tenha na reciclagem uma política propositiva de ponta. Dispensando essas estratégias, dificilmente o lixo domiciliar brasileiro deixará de ser 0 que é: uma questão polêmica por não se ajustar a uma gestão ótima dos resíduos.

Palavras-chave: resíduos sólidos domiciliares, lixo domiciliar brasileiro, modelos de gestão, impactos ambientais, Plano Nacional de Resíduos Sólidos.

\begin{abstract}
The question of management excellence for the final disposal of solid waste in Brazil has become a recurring theme in many segments of society and among experts. In addition to sanitary problem, the waste disposal management has vivid interfaces with the environmental issue and highlights as fundamental procedure for local authorities. Overall, the monitoring of waste calls for further equipment lacking in technical content (lixões) or, for landfills whose management is also subject to technical objections. The escalation in the generation of municipal waste has led to increasing scarcity of land for disposal, suggesting, for incineration as a solution for the disposal of waste. However, the thermal process inserts environmentally complicatingelements, implies a technical and efficient public service, assumptions that affect decisively in the implementation of incinerators. The Brazilian domestic waste, one of the largest amounts of a world scale, requests a management model that prioritizes the review of the processes that generate waste, starting with the habits of consumption, and also must have recycling policies proposals. Dismissing these strategies, hardly the Brazilian household waste will no longer be what it is: a controversial issue that does not fit the optimal management of waste.

Keywords: solid waste, brazilian household waste, models management, environmental impacts, National Solid Waste Plan.
\end{abstract}




\section{Résumé}

La question de l'excellence en gestion pour l'élimination finale des déchets solides au Brésil est devenu un thème récurrent dans de nombreux segments de la société et des experts. En plus de problème de santé, la gestion des déchets a des interfaces claire à la question de l'environnement et souligne comment la procédure fondamentale pour les autorités locales. Globalement, le suivi des déchets appels pour les équipements qui ont besoin d'un contenu technique (décharges) ou, pour les décharges dont la gestion est également soumise à des objections techniques. L'escalade dans la production de déchets municipaux a conduit à la pénurie croissante de terres pour l'élimination, suggérant, l'incinération comme une solution pour l'élimination des déchets. Toutefois, les processus thermique inserts des éléments de l'environnement qui le complique, et implique aussi un service public technique et efficace, des hypothèses qui affectent résolument dans la mise en œuvre des incinérateurs. Les déchets domestiques brésiliennes, de grandes quantités d'une échelle globale, les appels pour un modèle de gestion qui priorise l'examen des processus qui génèrent des déchets, à commencer par les habitudes de consommation, et a également un avantage politique de recyclage volontariste. Rejetant ces stratégies, à peine les déchets ménagers brésilienne ne sera plus ce qu'elle est: une question controversée correspond pas à la gestion optimale des déchets.

Mots-clés: déchets solides ménagers, déchets ménagers brésilienne, modèles de gestion, impacts environnementaux, Plan National des Déchets Solides.

\section{Introdução}

O lixo tem sido um problema recorrente em todo o país, agravado acintosamente pelas modalidades inadequadas de disposição final e de confinamento dos rejeitos, aspecto que na voz de inúmeros especialistas, além de gerar sérios desconfortos ambientais e sanitários, pode inviabilizar, até mesmo em médio prazo, a sociedade humana, ao menos tal como a conhecemos (Calderoni, 2003, p. 25). Objeto de recorrentes catilinárias, a aprovação do Plano Nacional de Resíduos Sólidos (PNRS, de 2 de agosto de 2010) traz novidades para o debate dessa questão, a começar, por exemplo, pela definição do que pode ser considerado como destinação final ambientalmente adequada para os resíduos (Capítulo II, Definições, §VII). De modo direto, a lei cita a reutilização, reciclagem, compostagem, recuperação e o aproveitamento energético do lixo, procedimentos respaldados por outras destinações admitidas pelos órgãos competentes do Sistema Nacional de Meio Ambiente (SISNAMA), Sistema Nacional de Vigilância Sanitária (SNVS) e Sistema Único de Atenção à Sanidade Agropecuária (SUASA). Quanto aos lixões - ícone máximo do desmazelo na gestão do lixo -, são proibidos, estabelecendo-se igualmente como obrigação dos municípios elaborar Planos de Gestão dos Resíduos, incentivar a Coleta Seletiva de Lixo, adotar a responsabilidade compartilhada e a gestão integrada do lixo. 


\section{A polêmica do lixo domiciliar brasileiro}

Cabe acautelar contra o otimismo fácil. Até por conta de uma tradição política profundamente enraizada no autoritarismo colonial (Duran, 2005), mesmo as decisões advindas da esfera institucional - que, portanto, emergem sob a tutela do status quo - estão sujeitas a pressões e contrapressões. Fato manifesto, determinações governamentais que afetam interesses hegemônicos corriqueiramente tornam-se letra morta, podendo esvaziá-las e torná-las inócuas e inoperantes. Caberia advertir: o lixo possui uma interface política, que se revela toda vez que se coloca o debate sobre sua destinação, gestão, discriminação de responsabilidades, encaminhamento das normatizações e, sumamente, a aplicação das leis. Nessa ponderação, não deixa de ser significativo que a Lei $\mathrm{n}^{0} 12.305$, que justamente instituiu o PNRS, tenha demorado 19 anos para ser sancionada, demonstração evidente de conflitos entre grupos de interesse e de divergências quanto à regulamentação da gestão dos rejeitos. Nesta ordem de colocações, o PNRS surgiu antes por ser inviável a continuidade da ausência de uma normatização para a gestão dos lixos - especialmente diante de um contexto em que passam a proliferar numa velocidade ainda maior - e não por boas intenções ambientais, de resto ausentes durante um longo período.

Ademais, seria necessário acompanhar com muita atenção a aplicação de um marco regulatório em um país onde a prática real cotidiana desafia implacavelmente a aplicação das legislações. Nesta senda, o Ministério do Meio Ambiente informou que em agosto de 2012, quando finalizou o prazo estipulado para os municípios apresentarem Planos de Gestão de Resíduos Sólidos, apenas 9,8\% das municipalidades haviam completado a elaboração do documento. A avaliação ganha contornos de maior gravidade quando se sabe que mesmo os planos elaborados apresentam muitas falhas técnicas e lacunas, como ausência de metas e de custos de implantação dos programas, transformando esses documentos em verdadeiros pronunciamentos retóricos (Antunes, 2012, passim; Waldman, 2012, 2010a e 2010b; Piva, 2008).

Arrematando, os óbices na implantação do PNRS decorrem tanto da herança deixada por sucessivas décadas de ausência de normatização institucional, quanto de questões de fundo conceitual-operacional. Isto sem contar contradições que pespontam no próprio corpo da legislação. ${ }^{2}$ 
Deste modo, embora colocados num patamar novo, existem elementos que permitem vaticinar a continuidade de impactos decorrentes da disposição final do lixo residencial ou domiciliar (RDO), tanto no que se refere aos métodos que se empenham em fazer o lixo desaparecer mediante sepultamento (aterros), quanto aos que advogam sua volatização recorrendo ao fogo das fornalhas (incineradores).

Fazendo primeiramente um apanhado crítico dos aterros, vejamos o que os levantamentos têm a nos dizer. Quanto a este método de disposição final, a Pesquisa Nacional de Saneamento Básico (PNSB) 2008, do IBGE, lançada em agosto de 2010, revela claramente um sequenciamento cronológico marcado pela diminuição dos lixões e expansão da implantação de aterros sanitários. Como é possível aferir, os dados revelam que em 2008 apenas $27,7 \%$ dos resíduos sólidos eram encaminhados para aterros sanitários. Outros 22,5\% dos resíduos sólidos domiciliares (RDO) seguiam para aterros controlados. E 50,8\% dos municípios mantinham lixões como instrumento básico de gestão dos RDO. Por sua vez, o relatório da Associação Brasileira de Empresas de Limpeza Pública e Resíduos Especiais (ABRELPE), ${ }^{3}$ precisando aportes com perfil gravimétrico de índole nacional, regional e estadual, cientifica que em 2009, na escala do país, 56,8\% dos resíduos sólidos urbanos (RSU) coletados foram recepcionados por aterros sanitários, cabendo 23,9\% aos aterros "controlados" e os restantes, 19,3\%, aos lixões (Relatório ABRELPE, 2010, p. 32). ${ }^{4}$

Isso posto, façamos então as considerações a que nos propusemos. Partindo de um ponto de vista conceitual, primeiramente seria indispensável admoestar que o entendimento do aterro sanitário como equipamento capaz de assegurar "destinação adequada” aos RDO está sujeito a diversas contestações. Os aterros utilizam vastas áreas de terrenos, envolvendo investimentos consideráveis para enterrar materiais passíveis de reutilização, um contrassenso evidente. Tecnicamente, tais "depósitos tecnogênicos construídos" - definição esta plena de geological flavour constituem instalações sujeitas a falhas operacionais e acidentes. Mesmo os aterros mais bem administrados e dotados com quadros técnicos de excelência são acometidos por sinistros, como o transbordamento e infiltração do chorume ${ }^{5}$ no solo, escapamento de jatos de gás, confinamento ignorado de restos perigosos, ${ }^{6}$ escorregamentos, recalques, trincamentos, rupturas e muitas outras ocorrências não previstas pelos planos operacio- 
nais dessas obras de engenharia (Waldman, 2010a, p. 158-162; 2006b, p. 261-262; Peloggia, 1998, p. 129-136).

Dessa forma, os aterros sanitários apenas poderiam ser catalogados como procedimento "adequado" se comparados com métodos ambientalmente ainda mais daninhos, como os lixões e os aterros "controlados". Numa definição sumária, o lixão consiste na "técnica" de depositar resíduos in natura de diversas procedências ${ }^{8}$ (construção civil, hospitalar, doméstico, industrial etc.) no ambiente, à revelia de qualquer estudo geotécnico, permitindo que o chumeiro e o metano ${ }^{9}$ escoem à vontade. Com um formato como este, o lixão poderia ser tranquilamente enquadrado no que Murray Bookchin (1989, p. 45), certa ocasião, definiu como repertório cotidiano da imoralidade da sociedade contemporânea. Em relação ao chamado aterro "controlado", suas características pouco diferem do modelo anterior, resumindo-se no mais das vezes a algum tipo de cuidado em minimizar a exposição do lixo e acomodá-lo com tratores e camadas de solo. ${ }^{10}$ Constitui, portanto, uma versão mascarada - ersatz - dos lixões.

Contudo, seja qual for o método de sepultamento dos rejeitos, seria cabível ponderar que essa medida - enterrar lixo -, seja de modo "ambientalmente correto" ou não, está na contramão da ecoeficiência e das posturas mais avançadas quanto à economia dos materiais. ${ }^{11} \mathrm{Na}$ verdade, os aterros, quando muito, conotam mausoléus de lixos, obras voltadas para encarcerar em rugosidades artificiais toneladas de materiais potencialmente úteis para a vida humana, formando montanhas cuja eloquência é diretamente proporcional à desfaçatez das suas dimensões. Estes são problemas emergenciais e merecedores de destaque imediato. Os aterros constituem verdadeiras usinas de calda negra e de gases de efeito estufa, "virtudes" estas elevadas ao paroxismo pelos lixões. Note-se então que, num plano espacial, os 50,8\% dos municípios brasileiros que adotam o vazadouro como "modalidade de gestão" dos RDO cobrem cerca de $80 \%$ do território nacional (Vide Figura 1). Verdadeiramente, trata-se de um território imenso exposto aos eflúvios, líquidos residuários e pestilências oriundos da putrefação descontrolada dos refugos. Esse espaço abriga o essencial das paisagens brasileiras de importância socioambiental - floresta amazônica, cerrado, pantanal, mangues, caatinga -, quinhão considerável dos mananciais de águas doces do país. Abriga diversificado conjunto de populações tradicionais - ribeirinhos, extrativistas, pequenos agricultores, nações indígenas, entre outras. Essa constatação, além de su- 
gerir acautelamento quanto à frieza dos números e um repensar sobre o quanto as estatísticas podem induzir a erros de avaliação, lembra-nos da gravidade ambiental configurada nos lixões. Mas, igualmente, incita-nos a questionar se os procedimentos administrativos estarão plenamente habilitados a dar conta de enterrar e gerenciar massas ainda maiores de rejeitos. No final das contas, estamos vivenciando tempos nos quais se observa uma verdadeira hipertrofia na geração de lixos.

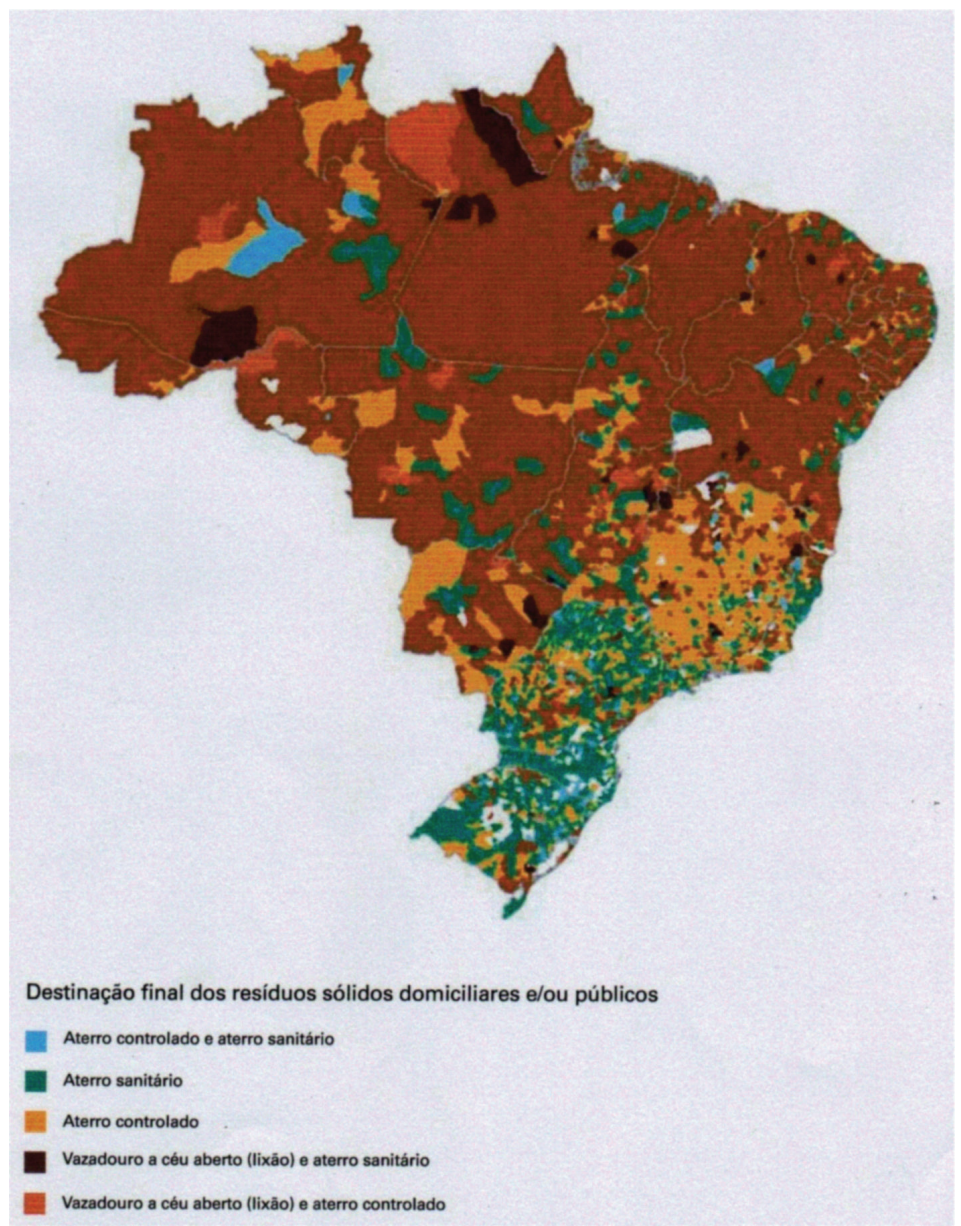

Figura 1 - Municípios, segundo a destinação final dos resíduos sólidos domiciliares e/ou públicos Fonte: Pesquisa Nacional de Saneamento Básico, 2008 
Cumpriria salientar, então, que depositar adequadamente os RDO em aterros sanitários não é propriamente uma solução. Além de sua probidade ser rotineiramente colocada em questão, ${ }^{12}$ a gestão destes equipamentos envolve riscos. Quando esgotados, demandam monitoramento para o acompanhamento das vultosas emanações de metano e dos líquidos percolados, que podem persistir durante décadas. Para se manterem níveis mínimos de segurança, administrar sistemas de aterros sugere uma linha de continuidade administrativa e um grau de competência operacional que não constituem, em absoluto, uma praxe nem dos Serviços de Limpeza Urbana (SLU) nem, tampouco, das administrações municipais (Waldman, 2010a, p. 183). A título de exemplo do espólio de problemas que solicitam monitoramento, o aterro sanitário São João, localizado na capital paulista, gera 13 litros de chorume por segundo. Embora constitua uma emissão aparentemente insignificante, esse volume significa 780 litros por minuto, 46.800 litros por hora e 1.123.200 litros por dia. Ou, então, algo como a capacidade de 11.230 caixas d'água por dia de percolado (Waldman, 2006b, p. 278). O problema, contudo, não está restrito à metrópole paulista. Na Região Metropolitana de Campinas, apenas dois antigos lixões, o Pirelli e o do Parque Santa Bárbara, geram 200.000 litros diários de lixiviado que seguirão regurgitando para os próximos quinze anos.

Estes seriam breves demonstrativos dos passivos ambientais dos rebotalhos a serem enfrentados agora e no futuro próximo, em espaços considerados nucleares tendo em vista a formação socioespacial brasileira. Por outro lado, não há estimativa - credível ou não - quanto à quantidade de chorume gerado por antigos lixões no conjunto do território nacional (seriam 12.000 no total), e muito menos uma cartografia do grau de intervenção administrativa empenhada em, ao menos, acompanhar os eflúvios oriundos de imensas massas de descartes. Outro problema, este premente pela sua determinação espacial, é a escassez de áreas para disposição de lixo domiciliar. Muitas metrópoles brasileiras não possuem estoque de terras disponíveis para a construção de novos aterramentos. Cada aterro que cessa suas atividades significa um desafio geralmente insolúvel. A título de exemplo, no estado de São Paulo, unidade líder da federação na engrenagem econômica e na geração de lixo, a Companhia Ambiental do Estado de São Paulo (CETESB) apontou, em um levantamento divulgado em 2011, que o número de cidades que exportam resíduos para aterros situados em outros municípios passou de 62, em 2002, para 156, em 2010 
(praticamente um quarto dos 645 municípios paulistas), número que superou 100\% em apenas oito anos. Em vários casos, o rejeito é transportado por mais de $100 \mathrm{~km}$ para ser despejado. ${ }^{13} \mathrm{Na}$ Região Metropolitana de Campinas (RMC), a segunda em importância no Estado, quatorze das dezenove cidades da aglomeração enviam seus rebotalhos para municípios vizinhos. Gravíssima é a situação da capital paulista, que exporta 100\% das quase 10.000 toneladas diárias de refugos domiciliares para sítios provisórios, localizados nos municípios do seu entorno. ${ }^{14}$ Aparentemente, parece estar se configurando uma situação em que, ao contrário dos lixões cuja sentença de morte solicitou amparo em decreto, os aterros se extinguirão unicamente pelo esgotamento funcional motivado pela carência de espaço, assim como pela fricção da distância, ${ }^{15}$ visto que o alongamento dos trajetos implica sobrecarregar os encargos logísticos e financeiros.

É desta maneira que a dimensão espacial abre brechas para que entrem em cena os incineradores. ${ }^{16}$ Um mapeamento sumário das dificuldades enfrentadas pelos aterros - utilização de áreas enormes, escassez de sítios para deposição, chorume, metano etc. - denuncia obstáculos diante dos quais as fornalhas despontam como metodologia imbatível para uma gestão ótima dos rejeitos. Rebatizados de "unidades de recuperação de energia” ou, ainda, de "termovalorizadores", estes equipamentos surgem como alternativa que, sendo única em vários casos, terminará, cedo ou tarde, também julgada como válida e adequada. ${ }^{17}$ Enquanto empreendimento técnico, a queima do lixo exibe em sua defesa primazias derivadas da tecnologia de ponta. A incineração propicia esterilização e desintoxicação dos resíduos, ao mesmo tempo que, volatizando boa parte dos restos, reduz sua massa (75\%) e seu volume (90\%). Benefícios que nos aterros funcionando com base nos ciclos do meio natural - demandariam muito mais tempo. Isso coaduna com a lógica de produção e consumo em vigor, pois, reduzindo a permanência do lixo no espaço, a incineração impede que os rebotalhos exercitem um regime de antinomias, antecipando-se aos possíveis curtos-circuitos que perturbariam a fruição do sistema de engenharia. ${ }^{18}$ Deste modo, a combustão potencializa a irrupção de novos produtos, possibilitando que os ciclos de produção possam fazer giros de capital cada vez mais rápidos.

Complementando, a novel geração de incineradores pode consubstanciar outros ganhos adicionais advindos do reaproveitamento energético dos restos. Rubricada como Waste-to-Energy (WTE) ou Energy-from-Waste 
(EFW), essa tecnologia, responsável pela aceitação e difusão do tratamento térmico do lixo nos últimos anos, capta a energia obtida da queima dos resíduos - especialmente dos que incorporam alto valor calorífico, como plásticos, papéis e têxteis -, tendo por contrapartida a geração de energia, água quente e vapor, e contando, ademais, com uma fonte de receita adicional materializada nos créditos de carbono, justa recompensa por banir do ambiente as emissões de gás metano. É por conta dos arrazoados que enaltecem a incineração e, especialmente, os incineradores WTE, que esta modalidade de gestão dos rejeitos materializaria uma espécie de Endlösung für den Abfall: uma Solução Final para o Lixo, ${ }^{19}$ crescentemente adotada em todo o mundo. ${ }^{20}$ Desse modo, no Brasil, os incineradores são efetivamente uma nova frente de negócios, articulando interesses de administrações municipais/estaduais com empresas europeias detentoras de know-how na incineração. Uma simples apuração na mídia eletrônica revela projetos em curso em Brasília, Belo Horizonte, Porto Alegre e Rio de Janeiro. São Bernardo do Campo, importante polo demográfico e de consumo no Grande ABC paulista, discute a implantação de um incinerador WTE doméstico a ser construído na área do antigo lixão do Alvarenga, atualmente desativado. ${ }^{21}$ No Recife, planeja-se um empreendimento para operar 1.350 toneladas/dia de rejeitos cotidianos. No estado de São Paulo, um convênio negociado entre a administração estadual e um consórcio alemão da Baviera planeja colocar em operação incineradores nas Regiões Metropolitanas de São Paulo, de Campinas e da Baixada Santista (ESP, 2010a; ESP, 2010b).

Entretanto, nem tudo conspira em favor da combustão dos rejeitos. Muitos estudiosos da tecnologia são incisivos em listar os problemas da incineração, certificando que queimar lixo, sem falar da dependência tecnológica e do custo elevado de operação e manutenção, ${ }^{22}$ produz componentes tóxicos presentes nos gases e nas cinzas finais da combustão. Dentre os poluentes gasosos, destacam-se as dioxinas e furanos, ${ }^{23}$ substâncias persistentes de natureza tóxica e carcinogênica. A estas, somam-se compostos clorados, metais pesados, gases sulfurosos, monóxido de carbono e óxidos de nitrogênio. No tocante às ejeções sólidas, as cinzas volantes - um material granulado muito fino - podem esgueirar-se incólumes pelos dutos de despoeiramento e ganhar o ambiente externo às fornalhas. Quando inaladas, são vetor para doenças respiratórias e diversos tipos de câncer. Por sinal, muitas sobras apresentam elevado nível de 
contaminação, criando embaraços para sua disposição final, fato muito claro nas polêmicas internacionais com foco no descarte das cinzas da incineração, sistematicamente vetada pelas autoridades de grande número de países (Novaes, 2008; Waldman, 2010a; Alier, 2005; Ziglio, 2005, p. 80; CEMPRE, 2010, p. 205-219; Connett, 1999, p. 16-17; Greenpeace International, 1991).

\section{Considerações finais}

Entrementes - e polemizando, por exemplo, com os que acreditam nas possibilidades infinitas da reciclagem -, é possível argumentar que em algum momento a gestão do lixo deve recorrer ao aterro ou mesmo aos incineradores. Imaginar a possibilidade de uma sociedade humana que não gere restos ou que recicle tudo não passa de uma peça de ficção, tão fantasiosa quanto as mitologias da suposta desmaterialização da economia ou a estratégia do Zero Waste (Alier, 2005). Nesse sentido, cabe argumentar que uma gestão de excelência dos RDO - assim como qualquer outra modalidade de gerenciamento em nível administrativo -, por mais aprimorado que seja o aparato tecnológico em questão, não pode dispensar bons operadores e equipes de trabalho respaldadas com boa capacitação. Com base nessa averbação, não está permitido ignorar a parcimônia no trato e manutenção dos equipamentos, e isso sem esquecer a confecção de prognósticos de longo prazo, reportando às possibilidades de o modelo atender às demandas que justificaram sua implantação.

Mais ainda, pensando a crise ambiental que salta à vista de todos, tudo está a sugerir medidas que se antecipem ao surgimento das adversidades. Daí a imperiosa necessidade de se repensar o modelo produtivo e de consumo que induziu o surgimento de uma crise, na gestão dos resíduos, sem igual na história da humanidade, uma consideração que no caso brasileiro deveria ser debatida com toda a seriedade que a questão envolve.

Essas questões, infelizmente, estão rigorosamente ausentes no cenário nacional referente à gestão dos resíduos domiciliares.

\section{Notas}

1. Este texto foi formatado com informações levantadas para elaboração do Relatório de Pesquisa de Pós-Doutorado Lixo Domiciliar no Brasil: Dinâmicas So- 
cioespaciais, Gestão de Resíduos e Ambiente Urbano, investigação desenvolvida por Maurício Waldman, no âmbito do Departamento de Geografia do Instituto de Geociências da Universidade Estadual de Campinas (UNICAMP), tendo por supervisor o Prof. Dr. Antônio Carlos Vitte. A iniciativa recebeu apoio do CNPq na forma de Bolsa de Pós-Doutorado, transcorrendo entre 1/1/2010 e 22/2/2011.

2. No que seria um detalhe quase alegórico, o mesmo parágrafo que enumera os procedimentos ambientalmente corretos para a destinação adequada dos restolhos adverte para se observarem normas operacionais específicas, "de modo a evitar danos ou riscos à saúde pública e à segurança, e minimizar os impactos ambientalmente adversos”. Ora, se os métodos são ambientalmente corretos, por que então evitar possíveis danos ou riscos, e minimizar impactos ambientais?

3. Associação Brasileira de Empresas de Limpeza Pública e Resíduos Especiais, entidade fundada em 1976, congregando as principais empresas de limpeza e disposição final do lixo no Brasil.

4. Precisando melhor a intenção destes levantamentos, atente-se que as estatísticas do IBGE referem-se ao destino dos resíduos, enquanto os dados da ABRELPE, à massa do lixo.

5. Além de chorume, o líquido recebe outras denominações: percolado, lixiviado, chumeiro e calda negra. O chorume é efluente muito perigoso, carregado de malevolência. Estudos técnicos salientam sua periculosidade ambiental, alçando patamar de impactos 200 vezes mais intensos que o esgoto quanto à demanda bioquímica de oxigênio (DBO), ou seja, atua como poderoso elemento destrutivo das águas doces.

6. Reservadamente, técnicos da área admitem ser impossível auditar plenamente massas gigantescas de lixo como as que ingressam nos aterros.

7. A adjetivação dos aterros sanitários como método "adequado" de confinamento dos refugos é comum nos relatórios e documentos das empresas que gerenciam aterros e/ou processam a coleta mecanizada do lixo domiciliar.

8. Recorde-se que a deposição de resíduos a céu aberto fora anteriormente considerada como ilegal pela Lei de Crimes Ambientais $n^{\circ}$ 9.605/1998 (Oliveira, 2011, p. 1; Piva, 2008, p. 115).

9. O metano é um efluente gasoso crucial da agenda das mudanças climáticas. Ainda que as emissões de metano sejam inferiores às do dióxido de carbono (tido como carro-chefe do efeito estufa), seu efeito é consideravelmente maior, cerca de 20 vezes mais. A discussão relacionada com o metano conquista especial relevância pelo fato de ser este gás dotado de preocupante implicação com o aquecimento global. Acredita-se que no Brasil, os RDO, devido ao elevado teor de matéria orgânica, representem cerca de $12 \%$ das emissões brasileiras do gás, sendo que a disposição final responde por 84\% desse valor (Waldman, 2010a, p. 109; Ibam, 2007a).

10. Note-se que a categoria dos aterros "controlados" frequenta unicamente os prontuários brasileiros relacionados aos RDO. A literatura técnica internacional solenemente desconhece esta classe de aterros, uma peça de ficção criada pelos legisladores para poupar as prefeituras de prestarem contas à justiça por abrigarem vazadouros, sumidouros e lixões. Tecnicamente, os aterros 
“controlados”, por não apresentarem técnicas minimamente viáveis para garantir proteção mesmo que mínima ao meio ambiente, configurariam no máximo um lixão “melhorado” (Waldman, 2010a, p. 157; Piva, 2008, p. 106).

11. O desperdício gigantesco de recursos naturais implícito nas práticas administrativas habituais de gestão dos RDO poderia ser sanado por políticas de apoio às cooperativas de catadores de recicláveis, permitindo geração de renda e trabalho, além de indiscutíveis ganhos econômicos e ambientais. Uma pesquisa do Instituto de Pesquisa Econômica Aplicada (IPEA) aponta que a substituição do confinamento dos rejeitos nos aterros pela reciclagem permitiria ganhos da ordem de R\$ 8 bilhões/ano, quantia que o mesmo estudo assinala ser três vezes maior que o orçamento do Ministério do Meio Ambiente. Os benefícios ambientais se ampliam ainda mais se forem computados os recursos economizados na descontaminação do ambiente com gases e descontaminação dos lençóis de águas doces (IPEA, 2010, p. 7).

12. Caberia advertir que muitas áreas classificadas e/ou consideradas como aterros sanitários não apresentam condições mínimas exigidas para a disposição segura dos resíduos, ou então carecem de gestão de excelência (Waldman, 2010a, p. 161-162; Leite, 2004, p. 102).

13. Esse é o caso dos detritos de diversas cidades da orla litorânea do estado de São Paulo. Itanhaém e Peruíbe transportam seus resíduos para o Aterro do Lara, situado na cidade de Mauá, no Grande ABC paulista. Caraguatatuba deposita seus rejeitos no Aterro Anaconda, em Santa Isabel.

14. Dos dois últimos grandes aterros paulistanos, o São João foi fechado em 2009, e o Bandeirantes está saturado desde 2007.

15. “A noção de distância não tem significação se não se faz referência à estrutura de classes e ao 'valor' dos lugares, tanto para os indivíduos, como para o capital” (Santos, 1978, p. 78).

16. Ao contrário dos aterros, para o incinerador a dimensão espacial conta quase unicamente enquanto uma nuança locacional, estando excluída enquanto fator para o processamento do lixo. O objetivo de um aterro é, cedo ou tarde, fazer os resíduos retornarem ao ambiente. O de um incinerador é expurgá-los do espaço até onde isto for possível. Por isso mesmo, uma planta de incineração, contrariamente aos aterros, pode em tese se manter no mesmo local indefinidamente. Na sua acepção funcional, os incineradores, ao substituírem as reações de putrefação e de degradação dos materiais por inputs proporcionados pela combustão, se posicionam como um objeto técnico exclusivamente coordenado pela ação humana e, portanto, inserido num sistema cujo funcionamento independe de quaisquer fluxos naturais. Daí que, geograficamente, o incinerador é, por definição, um ponto fixo espacial alimentado pelos fluxos dos resíduos que alimentam suas chamas, e os aterros, um ponto fixo que termina em algum momento esgotado pelo escoamento dos rejeitos.

17. Por sinal, o PNRS estabelece "incentivo ao desenvolvimento de sistemas de gestão ambiental e empresarial voltados para a melhoria dos processos produtivos e ao reaproveitamento dos resíduos sólidos, incluídos a recuperação e o aproveitamento energético" (Capítulo II, Dos Princípios e Objetivos, art. $7^{\circ}$, inciso XIV, grifos nossos). Nessa mesma direção, o Art. $9^{\circ}$, $\S 1^{\circ}$, prescre- 
ve: "Poderão ser utilizadas tecnologias visando à recuperação energética dos resíduos sólidos urbanos, desde que tenha sido comprovada sua viabilidade técnica e ambiental, e com a implantação de programa de monitoramento de emissão de gases tóxicos aprovado pelo órgão ambiental”.

18. Os curtos-circuitos referem-se aos "espasmos" que paralisam os ciclos artificiais que asseguram a reprodução do espaço habitado, comprometendo a fruição dos inputs e outputs que por ele perpassam (Santos, 1978, 1988, passim).

19. A terminologia Endlösung für den Abfall é um bordão de marketing de empresas alemãs especializadas na venda de incineradores. Todavia, a expressão já aparece em muitos documentos brasileiros, claro sinal de contatos entre essas empresas e parceiros locais.

20. A aceitação alcançada pelos projetos de incineração transparece nas planilhas globais de gestão do lixo. Em 2008, a França queimou 32\% dos rejeitos; a Alemanha, 35\%; Holanda, 39\%; Suécia, 49\%; e a Dinamarca, 54\%. Nos EUA e China, a combustão é vista como tábua da salvação para a gestão do lixo. Outros países, como o Canadá, às voltas com o esgotamento dos seus aterros, demonstram forte intenção em reforçar o uso desta tecnologia. Acredita-se que na Europa existiam 420 usinas WTE, em 2003, processando 58,5 milhões de toneladas de lixo domiciliar por ano. O Japão processa 40 milhões de toneladas, e os Estados Unidos, outros 29,4 milhões. Paralelamente à clientela tradicional, os incineradores passaram a se disseminar por todo o mundo, instalando-se em países carentes de tradição na combustão dos rebotalhos (apud Waldman, 2011b).

21. Comumente, um fixo relacionado com o lixo atua como suporte para outros fixos que o sucedem. Este seria um caso típico da força inercial materializada nos objetos espaciais do lixo, ou, em outras palavras, da sua capacidade em revivificar processos e dinamismos socioespaciais (Santos, 1978).

22. Em muitos países dissolutamente perpassados por dessimetrias sociais, o encarecimento do sistema de gestão do lixo, além de significar expansão da participação do tratamento dos resíduos na contabilidade administrativa geral, tem por desdobramento a transferência de renda dos setores mais pobres (geradores de pouco lixo) para as classes ricas (geradoras da maior parte do lixo urbano), o que ocorre pelos próprios mecanismos de tributação que não distinguem responsabilidades pontuais e sequer o alcance do atendimento.

23. Cabe ressalvar que a emissão de dioxinas e furanos tem como ser evitada a partir de temperaturas acima de $900^{\circ} \mathrm{C}$. Entrementes, este coeficiente é difícil de se obter devido à presença, na massa de resíduos, de lixo úmido (abundante no lixo domiciliar brasileiro), que, arrefecendo o calor das fornalhas, uma vez mais contribui para o encarecimento das operações.

\section{Referências}

ABRELPE. Associação Brasileira de Empresas de Limpeza Pública e Resíduos Especiais. Panorama dos resíduos sólidos no Brasil, 2009-2010.

ALIER, Juan Martinez. El ecologismo de los pobres - conflictos ambientales y lenguajes de valoración. Barcelona, Espanha: Icaria-Antrazyt-Flacso, 2005. 
ANTUNES, André. Lixo: o lado oculto (mas lucrativo) do consumo. Revista POLI, n. 25, p. 2-11, nov. 2012. Escola Politécnica de Saúde da Fundação Oswaldo Cruz (Fiocruz). Rio de Janeiro (RJ): Fiocruz, 2012.

BOOKCHIN, Murray. Sociobiologia ou ecologia social?. Lisboa (Portugal): Sementeira, 1989.

BRASIL. Lei de Crimes Ambientais. Lei n. 9.605, de 12 de fevereiro de 1998. Dispõe sobre as sanções penais e administrativas derivadas de condutas e atividades lesivas ao meio ambiente, e dá outras providências. Disponível em: <http://www. planalto.gov.br/ccivil_03/Leis/L9605.htm>. Acesso em: 20/2/2011.

BRASIL. Lei $n^{\circ}$ 12.305, de 2/8/2010. Institui a Política Nacional de Resíduos Sólidos (PNRS); altera a Lei no 9.605, de 12/2/1998; e dá outras providências. Disponível em: <http://www.planalto.gov.br/ccivil_03/_ato2007-2010/2010/lei/l12305.htm>. Acesso em: 11/10/2010.

CALDERONI, Sabetai. Os bilhões perdidos no lixo. 4. ed. São Paulo: Humanitas/ FFLCH-USP, 2003. p. 25.

CEMPRE - Compromisso Empresarial para Reciclagem. Lixo Municipal: Manual de Gerenciamento Integrado. 3. ed. São Paulo: IPT - Instituto de Pesquisas Tecnológicas/CEMPRE, 2010.

CETESB - Companhia Ambiental do Estado de São Paulo. Secretaria de Estado do Meio Ambiente. Disponível em: <http://www.cetesb.sp.gov.br/CETESB>.

CONNETT, Paul. Incineração do lixo municipal - uma solução pobre para o século XXI. Palestra apresentada na $4^{\mathrm{a}}$ Conferência Anual de Administração Internacional de Lixo-para-Energia, Holanda, 24-25/11/1998. Tradução de Carlos Eugênio Soto Vidal e Doralice Pedroso de Paiva, pesquisadores da Embrapa Suínos e Aves, Santa Catarina, Brasil, 1999.

DURAN, Marina. O medo e os vínculos sociais no brasil. Tese (Doutorado em Ciências Sociais) - Pontifícia Universidade Católica de São Paulo, São Paulo, 2005.

ESP - Gerenciamento de resíduos sólidos: uma visão de futuro. Governo do Estado de São Paulo: Secretaria do Meio Ambiente (SMA) e Companhia Ambiental do Estado de São Paulo (CETESB), edição bilíngue inglês/português, 2010a.

ESP - Implantação de central de tratamento térmico de resíduos no Estado de São Paulo: tratamento térmico para aproveitamento energético, Sumário Executivo. Governo do Estado de São Paulo: Secretaria de Estado de Saneamento e Energia, 2010b.

GREENPEACE. A Report on the Hazardous Waste Incineration Crisis. Amsterdã (Países Baixos): Greenpeace International, 1991.

IBAM - Instituto Brasileiro de Administração Municipal. Mecanismo de desenvolvimento limpo - redução de emissões na disposição final. Rio de Janeiro: IBAM, 2007a.

IBGE - Instituto Brasileiro de Geografia e Estatística. Pesquisa Nacional de Saneamento Básico - PNSB 2008. Ministério do Planejamento, Orçamento e Gestão. Rio de Janeiro: IBGE, 2010. 
IPEA - Instituto de Pesquisa Econômica Aplicada. Pesquisa sobre pagamento por serviços ambientais urbanos para gestão de resíduos sólidos. Brasília (DF): Secretaria de Assuntos Estratégicos da Presidência da República, Diretoria de Estudos e Políticas Regionais, Urbanas e Ambientais (DIRUR), 2010. p. 7.

LEITE, T. M. C. Entraves espaciais: análise de brownfields representados por aterros de resíduos sólidos urbanos desativados no município de São Paulo. Exame de Qualificação (Doutorado) - Universidade Estadual Paulista, Unesp, Rio Claro (SP), 2004. p. 102.

NOVAES, Washington. O lixo, agora entre avanços e dúvidas. O Estado de São Paulo, 7/1/2008. Disponível no site do Jornal da Ciência, órgão da Sociedade Brasileira para o Progresso da Ciência (SBPC): <http://www.jornaldaciencia.org. br/Detalhe.jsp?id=75750 > . Acesso em: 11/1/2011.

OLIVEIRA, Richard Geraldo Dias de. Texto-base para Audiência Pública Workshop: Destinações finais dos resíduos sólidos - soluções metropolitanas. Ordem dos Advogados do Brasil, 73ª Seção de Guarujá (SP), 23/2/2011. p. 1.

PELOGGIA, Alex. O homem e o ambiente geológico: geologia, sociedade e ocupação humana no município de São Paulo. São Paulo: Xamã, 1998. p. 129-136.

PIVA, Ana Luiza. Direito ambiental, sustentabilidade e cultura: um enfoque sobre a responsabilidade ambiental pós-consumo. Tese (Doutorado em Direito) Pontifícia Universidade Católica do Paraná, Curitiba, 2008. p. 106 e 115.

SANTOS, Milton. Metamorfoses do espaço habitado: fundamentos teóricos e metodológicos da Geografia. Texto escrito com a colaboração de Denise Elias. São Paulo: Hucitec, 1988.

. Manual de Geografia Urbana. São Paulo: Hucitec, 1981. (Col. Geografia: Teoria a Realidade).

. Por uma Geografia nova. São Paulo: Hucitec-Edusp, 1978. p. 78.

WALDMAN, Maurício. A civilização do lixo. Entrevista. Revista IHU - Instituto Humanitas Unisinos, São Leopoldo (RS), n. 410, p. 5-9, dez. 2012. Edição especial sobre resíduos sólidos: A era do lixo.

Lixo domiciliar no Brasil: dinâmicas socioespaciais, gestão de resíduos e ambiente urbano - Relatório de Pesquisa de Pós-Doutorado. Campinas: Unicamp-CNPq, 2011a.

. A civilização do lixo: contradições, limites e esgotamento. Campinas: mimeo Unicamp, 2011b.

. Descomplicar a reciclagem. Depoimento prestado para a Coluna de Celso Ming, edição de 20-01-2011, Jornal O Estado de S. Paulo (OESP), São Paulo, p. B2.

. Lixo: cenários e desafios - abordagens básicas para entender os resíduos sólidos. São Paulo (SP): Cortez, 2010a. p. 109, p. 157-162, p. 183.

Política Nacional de Resíduos Sólidos: faltou repensar. São Paulo (SP): Cortez Editora, 2010b. Artigo eletrônico disponibilizado a partir de outubro de 2010 no site da Cortez Editora: <http://www.cortezeditora.com.br/artigomauriciowaldman2.html>. 
. Lixo extraordinário. Depoimento concedido a respeito da questão dos resíduos sólidos. Ideia Sustentável, n. 22, p. 20-31, dez. 2010. 2010c. Disponível em: <http://www. ideiasustentavel.com.br/2011/01/especial-residuos-\%E2\%80\%93-lixo-extraordinario/>.

. Cultura do obsoleto deve ser esquecida, afirma consultor. Entrevista para a Folha de São Paulo, Cad. de informática, 22/3/2009.

. Meio Ambiente \& Antropologia. 1. ed. São Paulo (SP): Senac, 2006a. (Série

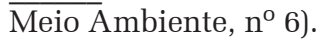

. Água e metrópole: limites e expectativas do tempo. Tese (Doutorado em Geografia) - Depto. de Geografia da FFLCH/Universidade de São Paulo, São Paulo, 2006b. p. 261-262, p. 278. Disponível em: <http://www.teses.Usp.br/teses/ disponiveis/8/8136/tde-20062007-152538/>. Acesso em: 12/11/2010.

ZIGLIO, Luciana. A Convenção de Basileia e o destino dos resíduos industriais no Brasil. Dissertação (Mestrado em Geografia) - Departamento de Geografia, Universidade de São Paulo, São Paulo, 2005.

Maurício Waldman - Licenciado em Ciências Sociais pela Universidade de São Paulo - Mestre em Antropologia Social e Doutor em Geografia pela mesma universidade - Pós-Doutor pela Universidade Estadual de Campinas. É pesquisador, professor universitário, consultor ambiental e escritor. Desenvolve seu $2^{\circ}$ Pós-Doutorado na Universidade de São Paulo. Exerceu a chefia da Coleta Seletiva de Lixo da capital paulista e a coordenadoria do Meio Ambiente em São Bernardo do Campo. Desde 2012 é consultor internacional da AFRO-CHAMBER: Câmara de Comércio Afro-Brasileira.

Recebido para publicação em 5 de fevereiro de 2013 Aceito para publicação em 12 de maio de 2013 